See discussions, stats, and author profiles for this publication at: https://www.researchgate.net/publication/345435782

\title{
DEVELOPMENT OF NOVEL MICROSTRUCTURED LIPID CARRIERS FOR DISSOLUTION RATE ENHANCEMENT OF ALBENDAZOLE
}

Article in International Journal of Applied Pharmaceutics · November 2020

4 authors:

Jose Alexis Castro-Alpízar University of Costa Rica 3 PUBLICATIONS 5 CITATIONS SEE PROFILE

Ronny Vargas

University of Barcelona 7 PUBLICATIONS 6 CITATIONS

SEE PROFILE

Some of the authors of this publication are also working on these related projects:
READS

59

Jorge Pacheco

University of Costa Rica

5 PUBLICATIONS 12 CITATIONS

SEE PROFILE

German Madrigal

University of Costa Rica

28 PUBLICATIONS 30 CITATIONS

SEE PROFILE

Dermocosmetic Formulations View project

Aplicación de la espectroscopia óptica al análisis de los productos de la industria farmacéutica View project 


\section{DEVELOPMENT OF NOVEL MICROSTRUCTURED LIPID CARRIERS FOR DISSOLUTION RATE ENHANCEMENT OF ALBENDAZOLE}

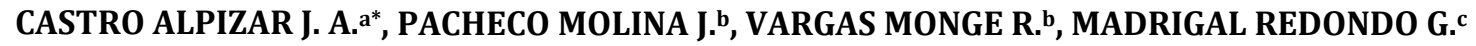

aFaculty of Pharmacy, University of Costa Rica, San Jose, Costa Rica, bLaboratory of Pharmaceutical Technology, Faculty of Pharmacy, University of Costa Rica, San Jose, Costa Rica, cLaboratory of Biopharmacy and Pharmacokinetics (LABIOFAR), Institute of Pharmaceutical Research (INIFAR), Faculty of Pharmacy, University of Costa Rica, San José, Costa Rica Email: castro2593@hotmail.com

Received: 05 Jul 2019, Revised and Accepted: 14 Aug 2020

\section{ABSTRACT}

Objective: This study aimed to develop a microstructured lipid carrier that improves the rate of dissolution of the active pharmaceutical ingredient (API) Albendazole.

Methods: A solvent diffusion method was used for the development of microstructured lipid carriers. The developed carriers were characterized by optical microscopy, infrared spectroscopy, differential scanning calorimetry (DSC), X-ray diffractometry (XRD), and dissolution testing.

Results: The morphology of the carriers was irregular, and their size tends to decrease with the addition of modifiers. Furthermore, the diffractograms and the thermograms indicated a loss of crystallinity. The thermograms and infrared spectra showed that there are not chemical incompatibilities between the API and the excipients. When the lipid carrier particles were modified with Aerosil@ 200 (specifically when using this excipient at a level of $6 \% \mathrm{w} / \mathrm{w}$ ), dissolution was increased up to $85.96 \pm 1.17 \%$ of the drug content as per USP test for Albendazole tablets in comparison with $36.13 \pm 0.52 \%$ for a lipid carrier formulation without modifiers.

Conclusion: It was demonstrated that it is possible to develop a modified lipid carrier that improves the dissolution rate of an API with a low solubility, which was related to the amorphization of the API crystalline structure.

Keywords: Albendazole, Microstructured lipid carrier, Dissolution, Crystalline structure

(C) 2020 The Authors. Published by Innovare Academic Sciences Pvt Ltd. This is an open access article under the CC BY license (http://creativecommons.org/licenses/by/4.0/) DOI: http://dx.doi.org/10.22159/ijap.2020v12i6.34782. Journal homepage: https://innovareacademics.in/journals/index.php/ijap

\section{INTRODUCTION}

Current methods of drug delivery aim to facilitate the arrival of the API to a specific therapeutic target. One of the main considerations for oral administration of drugs is to ensure the dissolution of the active pharmaceutical ingredients. To achieve this, it is possible to use drug delivery systems based on micro and nanotechnology. Within these systems, lipid carrier particles are becoming more popular, because this type of materials are easy to characterize and can be use in different administration routes [1].

The use of lipid materials as a matrix for microspheres can have some advantages. For example, these kinds of materials are usually biocompatible, biodegradable, non-immunogenic, and they are not expensive [2]. One of their main advantages is that they allow to encapsulate a great variety of non-water soluble compounds [2-4]. Among these compounds, these carriers could be useful to the class II drugs according to the Biopharmaceutical Classification System, which are characterized by showing a low aqueous solubility and high membrane permeability. These characteristics cause a limited absorption due to a low dissolution rate [3]. An example of this kind of drug is Albendazole (ABZ), which has a low bioavailability that is attributed to its low aqueous solubility, which is considered the ratelimiting step for its absorption [5].

This research aims to study the effect on the dissolution rate for ABZ from lipid carrier particles modified with different excipients, to favor the fast disintegration of the lipid matrix and the release of the API. Specifically, the incorporation of a pore-forming agent (Aerosil ${ }^{\circledR} 200$ ), a disintegrant (crospovidone), and the combination of both were tested.

Additionally, the improvement in the dissolution rate of ABZ would allow its application in different pathologies that need the drug to reach systemic circulation (for example neurocysticercosis).

Currently, it is common to achieve an improvement in the dissolution rate of poorly soluble drugs through the formulation of complexes with cyclodextrins and solid dispersions, which can be costly and not as effective when developing in vivo trials. The advantages of formulating a lipid carrier are improving a drug's dissolution and in vivo absorption, high biocompatibility, and its low cost compared to other microparticle manufacturing techniques. This type of lipid carriers could be tested in other pharmaceutical ingredients that need significant improvements in their dissolution rates.

\section{MATERIALS AND METHODS}

\section{Chemicals and reagents}

The reagents used were hydrochloric acid, Aerosil® 200 (colloidal silica), ABZ, crospovidone, ethanol, sodium hydroxide, methanol, glyceryl monostearate, polyethylene glycol 6000 (PEG 6000), polyvinylpyrrolidone $\mathrm{K} 25$, and caprylic/capric triglyceride.

\section{Preparation of lipid carriers}

The solvent diffusion method for the formation of nanostructured lipid carriers, described by $\mathrm{Hu}$ et al., was followed with some modifications [6]. The API was dissolved in $25 \mathrm{ml}$ of acidified methanol, then the glyceryl monostearate, the caprylic/capric triglyceride, and the polyethylene glycol 6000 (PEG 6000) were dissolved in the ABZ solution, with manual agitation, on a water bath at $55{ }^{\circ} \mathrm{C}$. The resultant organic solution was rapidly dispersed into $100 \mathrm{ml}$ of $0.2 \%$ polyvinylpyrrolidone $\mathrm{K} 25 \mathrm{w} / \mathrm{v}$ aqueous solution, under mechanical stirring at $600 \mathrm{rpm}$ on a water bath at $55^{\circ} \mathrm{C}$ for 3 min. Then $300 \mathrm{ml}$ of cold distilled water $\left(5-10^{\circ} \mathrm{C}\right)$ was added and the dispersion was transferred to an ice bath, maintaining the agitation. Stirring was stopped when the dispersion reached a temperature of about $20{ }^{\circ} \mathrm{C}$. It was left to rest and then the supernatant liquid was decanted. The microparticles were placed on absorbent paper towels and were allowed to dry at room temperature for $24 \mathrm{~h}$ in a desiccator with silica. The modifying agents (Aerosil ${ }^{\circledR} 200$ and/or crospovidone), were added in the organic solution at different proportions, following the same methodology described above. The exact composition of all carriers prepared is given in table 1. 
Table 1: Formulations of the microstructured lipid carriers $(\% \mathrm{w} / \mathrm{w})$

\begin{tabular}{|c|c|c|c|c|c|c|c|c|c|c|c|c|}
\hline & F1 & F2 & F3 & F4 & F5 & F6 & F7 & F8 & F9 & F10 & F11 & F12 \\
\hline PEG 6000 & 42.5 & 41.5 & 40.5 & 39.5 & 39.0 & 38.5 & 41.5 & 40.5 & 39.5 & 39.5 & 39.5 & 39.5 \\
\hline Glyceryl monostearate & 31.9 & 31.1 & 30.4 & 29.6 & 29.2 & 28.9 & 31.1 & 30.4 & 29.6 & 29.6 & 29.6 & 29.6 \\
\hline Caprylic/capric triglyceride & 10.6 & 10.4 & 10.1 & 9.9 & 9.8 & 9.6 & 10.4 & 10.1 & 9.9 & 9.9 & 9.9 & 9.9 \\
\hline $\mathrm{ABZ}$ & 15.0 & 15.0 & 15.0 & 15.0 & 15.0 & 15.0 & 15.0 & 15.0 & 15.0 & 15.0 & 15.0 & 15.0 \\
\hline Aerosil $^{\circledR} 200$ & 0.0 & 2.0 & 4.0 & 6.0 & 7.0 & 8.0 & 0.0 & 0.0 & 0.0 & 1.5 & 3.0 & 4.5 \\
\hline Crospovidone & 0.0 & 0.0 & 0.0 & 0.0 & 0.0 & 0.0 & 2.0 & 4.0 & 6.0 & 4.5 & 3.0 & 1.5 \\
\hline
\end{tabular}

ABZ: albendazole; PEG 6000: polyethylene glycol 6000

\section{Carrier's characterization}

\section{Morphology and size}

The shape and size of the lipid carriers were determined with an Olympus CX31 optical microscope, the samples were visualized with a magnification setting of $40 \mathrm{X}$ and were analyzed using ImageJ software.

\section{Differential scanning calorimetry (DSC)}

A Setline ${ }^{\circledR}$ STA/STA+calorimeter (Setaram) was employed. Approximately $10 \mathrm{mg}$ of the samples were put in the aluminum sample holders. The scan rate was $10^{\circ} \mathrm{C} / \mathrm{min}$ in the $25^{\circ} \mathrm{C}-250{ }^{\circ} \mathrm{C}$ temperature range. The analysis was developed under a helium purge and an empty aluminum sample holder was used as the reference.

\section{$\mathrm{X}$-ray diffraction (XRD)}

We analyzed samples in a Bruker D8 Advanced powder X-ray diffractometer. The source used was $\mathrm{Cu} \mathrm{K} \alpha 1-\mathrm{K} \alpha 2$, with Bragg Bentano configuration and Linx-eye linear detector. We collected the data in a $2 \theta$ range from $5^{\circ}$ to $50^{\circ}$ with $0.020^{\circ}$ per step and a speed per step of $384 \mathrm{~s}$.

\section{Fourier-transform infrared spectroscopy (FT-IR)}

We used a Perkin Elmer FT-IR spectrometer spectrum 1000 with potassium bromide disks and a lithium tantalate detector to collect FT-IR spectra, with a rate of $0.3 \mathrm{~cm} / \mathrm{s}$ and a resolution of $4.0 \mathrm{~cm}^{-1}$, in intervals of $2.0 \mathrm{~cm}^{-1}$. All spectra were recorded from $4000 \mathrm{~cm}^{-1}$ to $400 \mathrm{~cm}^{-1}$.

\section{Drug loading and encapsulation efficiency}

We followed the methodology for content uniformity described in the monograph of ABZ tablets in USP40 with some modifications [7]. We analyzed each formulation in triplicate. We transferred samples of microparticles equivalent to $40 \mathrm{mg}$ of $\mathrm{ABZ}$ (according to the theoretical amount in the formulation) to $100 \mathrm{ml}$ volumetric flasks. Then, we added about $60 \mathrm{ml}$ of acidified methanol, and mechanically stirred the flasks for $30 \mathrm{~min}$. Finally, we diluted the solutions with acidified methanol up to a volume of $100 \mathrm{ml}$.

We filtered a portion of each solution, discarding the first $20 \mathrm{ml}$. Then, we transferred $1.0 \mathrm{ml}$ of the filtrate to a $200 \mathrm{ml}$ volumetric flask, and diluted it with $0.1 \mathrm{~N}$ sodium hydroxide up to a volume of $200 \mathrm{ml}$. We measured the absorbance of these solutions and the standard solution at the wavelength of maximum absorption, at approximately $308 \mathrm{~nm}$. We used $0.1 \mathrm{~N}$ sodium hydroxide as the blank solution.

Calculations were performed as follows:

$$
\begin{gathered}
\text { ABZ amount }(\mathrm{mg})= \\
20\left(\text { Concentration of ABZ standard solution }\left(\frac{\mu \mathrm{g}}{\mathrm{ml}}\right)\right) \times \frac{\text { sample absorbance }}{\text { standard solution absorbance }} .
\end{gathered}
$$

$$
\text { Drug loading }(\%)=\frac{\mathrm{ABZ} \text { amount }}{\text { carriers weight }(\mathrm{mg})} \times 100 \ldots \ldots . .(2)
$$$$
\text { Encapsulation efficiency }(\%)=\frac{\text { ABZ amount }}{\text { Theoretical drug quantity }(\mathrm{mg})} \times 100 \ldots
$$

\section{Dissolution test}

We followed the methodology described in the monograph of ABZ tablets of USP40 [7]. The dissolution medium was $900 \mathrm{ml}$ of $0.1 \mathrm{~N}$ hydrochloric acid at $37^{\circ} \mathrm{C} \pm 0.5^{\circ} \mathrm{C}$ and dissolution apparatus 2 was used at $50 \mathrm{rpm}$ for $30 \mathrm{~min}$. We used samples of micro particles equivalent to $200 \mathrm{mg} \mathrm{ABZ}$ (based on the results of drug loading assay). To facilitate the incorporation and wetting of the lipid carriers with the dissolution medium, we mixed the dry particles with $3 \% \mathrm{w} / \mathrm{w}$ sodium lauryl sulfate for three minutes before adding them to the dissolution medium. We analyzed each formulation in triplicate.

We transferred a volume of $10.0 \mathrm{ml}$ of a filtered portion of the solution under test to a $250 \mathrm{ml}$ volumetric flask, and then diluted it with $0.1 \mathrm{~N}$ sodium hydroxide to volume. We measured the absorbance of these solutions and the standard solution at the wavelength of maximum absorption, at approximately $308 \mathrm{~nm}$, using $0.1 \mathrm{~N}$ sodium hydroxide as the blank solution.

Calculations were performed as follows:

$$
\begin{gathered}
\text { ABZ amount }(\mathrm{mg})= \\
22,5\left(\text { Concentration of ABZ standard solution }\left(\frac{\mu \mathrm{g}}{\mathrm{ml}}\right)\right) \times \frac{\text { sample absorbance }}{\text {.... (4) }} \\
\text { ABZ released }(\%)=\frac{\mathrm{ABZ} \text { amount }}{200 \mathrm{mg}} \times 100 \ldots . . .(5)
\end{gathered}
$$

\section{Data analysis}

The data are expressed as mean \pm SD and were compared by oneway ANOVA, followed by Tukey post hoc test. The differences were considered statistically significant when $p<0.05$. The analysis was performed using the GraphPad Prism 5 software and Microsoft Excel 2016.

\section{RESULTS AND DISCUSSION}

The particle size determination of the carriers is given in fig. 1. In general, it is noted that with the addition of Aerosil ${ }^{\circledR} 200$ in concentrations above $4 \%$, and in all the formulations with crospovidone or the combination of Aerosil ${ }^{\circledR} 200$-crospovidone, a decrease in the maximum particle size of the carriers is obtained, in comparison with the formulation without modifying agents (F1).

Aerosil $^{\circledR} 200$ has been reported as a viscosity-increasing agent [8, 9], which generates a decrease in the size of the microparticles [8].

Regarding the effect of crospovidone, when we putted the disintegrants in contact with a suitable fluid, they swollen and increased their size. The absorption of the liquid leads to an increase in the effective concentration of the solutes and to a decrease in the volume of free fluid, which reduces the movement of the liquid and this generates the increase in viscosity [10].

Although we originally added both excipients in the organic phase, it should be considered that a certain amount could have passed to the aqueous phase. In that case, an increased viscosity has the effect of producing a higher degree of dispersion of the organic phase, forming smaller globules that after solvent diffusion and cooling will generate smaller solid microparticles.

When we examined the morphology of these carriers, as shown in fig. 2, we found that they had irregular shapes and sizes. 


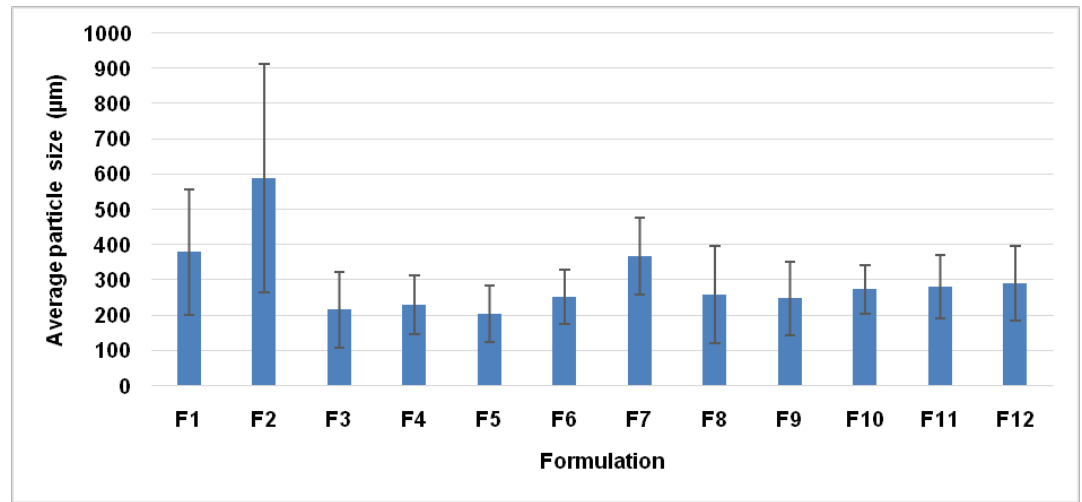

Fig. 1: Size determination of the microstructured lipid carriers, data given in mean $\pm S D ; n=15$

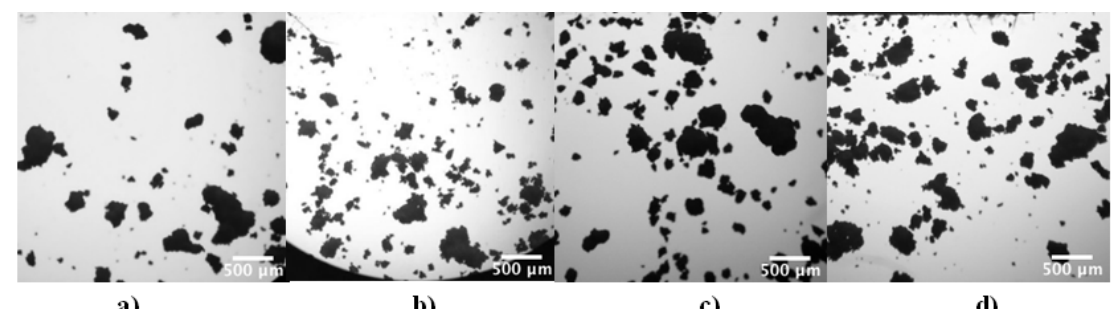

a)

b)

c)

d)

Fig. 2: Morphology of the microstructured lipid carriers. F1 (a), F4 (b), F8 (c) and F11 (d)
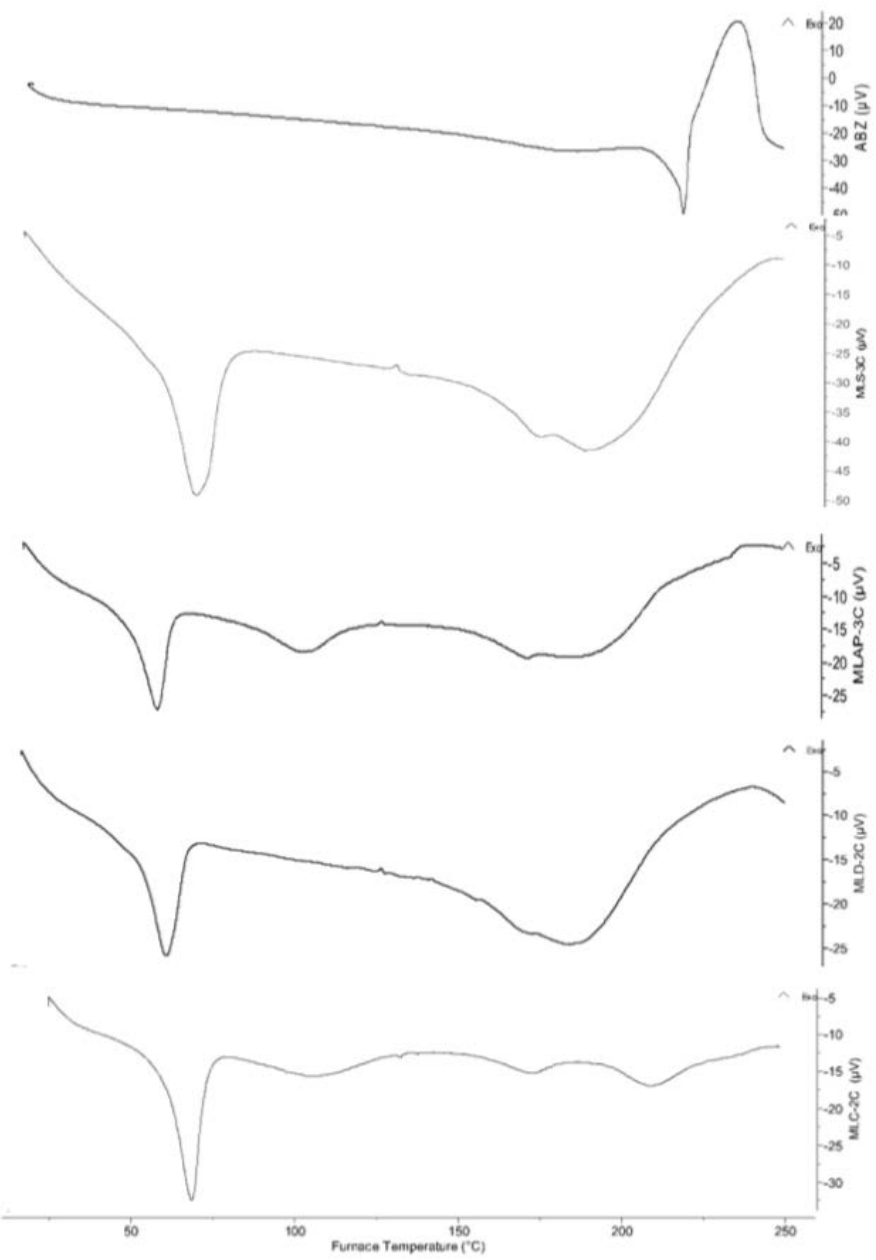

Fig. 3: Thermograms of the carriers developed. In descending order: albendazole (ABZ), F1, F4, F8 and F11 
The thermograms obtained for the carriers developed are shown in fig. 3. There are two endothermic transitions, the first is between 60 $70{ }^{\circ} \mathrm{C}$ and the second is a broad and slightly pronounced peak before $200{ }^{\circ} \mathrm{C}$. The first transition is related to the melting of the matrix and the second transition is related to the melting of the API. However it is noted that the peak does not have the same characteristics as the peak registered for pure ABZ. The absence of the endothermic peak of the API can be attributed to the dissolution of the API in the molten matrix $[11,12]$, or the loss of crystallinity of the drug, i.e. it becomes an amorphous solid [12,13]. We can assume a change in

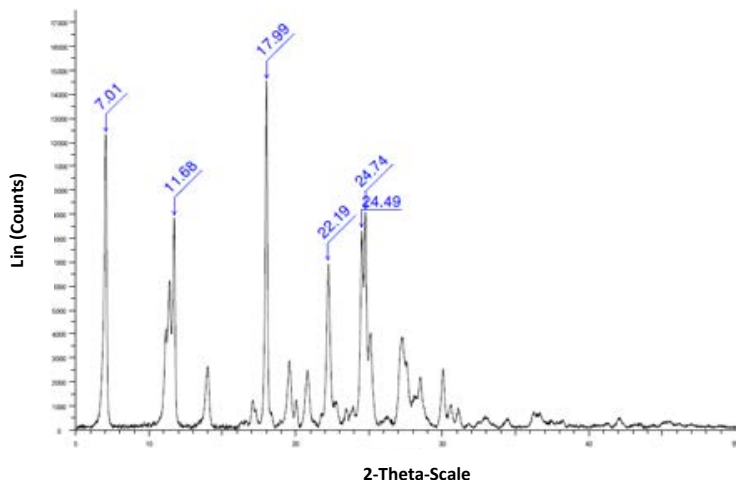

a)

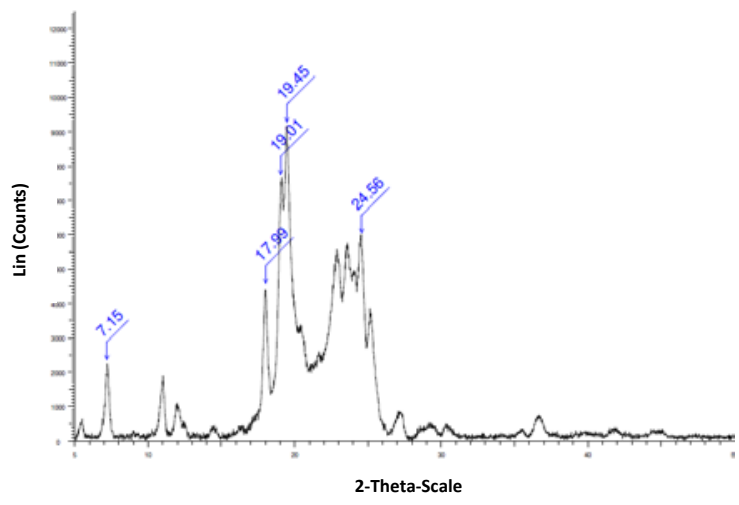

c)

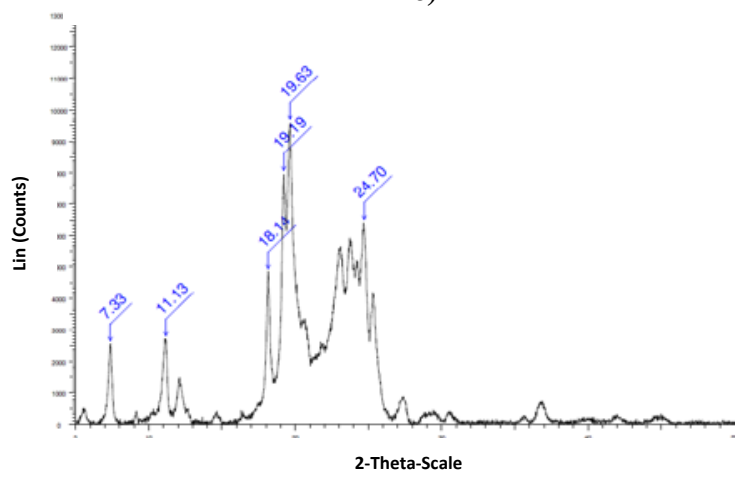

e) the crystalline structure of the compound, since the fusion occurs at a lower temperature and the peak is wider and less intense than that corresponding to the pure drug [9].

Diffractograms from the XRD assay are shown in fig. 4. The carriers designed clearly show the presence of the signals assigned to the API, which indicates the absence of chemical interactions between the components. However, these characteristic transitions of the API decrease in intensity, which confirms a loss of the crystallinity of the ABZ [14].

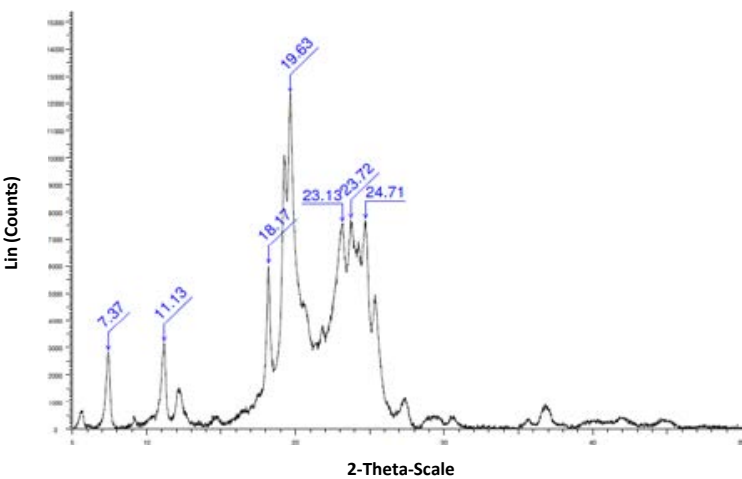

b)

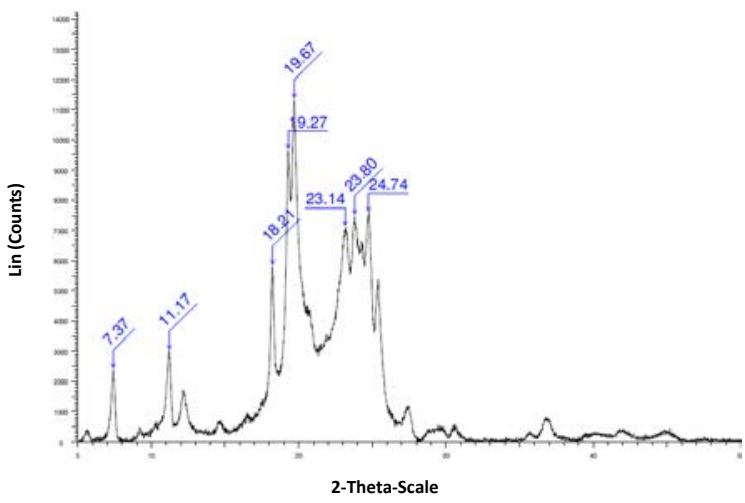

d)

Fig. 4: X-ray diffractograms of Albendazole (ABZ) (a), F1 (b), F4 (c), F8 (d) and F11 (e)

The IR spectra of ABZ and the carriers are shown in fig. 5. The main API-related signals show no changes in the carriers' spectra, which indicates that there are no chemical interactions between the API and the excipients. It can be seen that the absorption band at $3324 \mathrm{~cm}^{-1}$ in the carriers spectra becomes a little wider than in the original spectrum of ABZ, which is attributed to the stretching vibrations of the $\mathrm{O}-\mathrm{H}$ bond presents in glyceryl monostearate and
PEG $6000[15,16]$. Another difference found in the carriers' spectra consists of two intense peaks present approximately at $2915 \mathrm{~cm}^{-1}$ and $2849 \mathrm{~cm}^{-1}$, which represent $\mathrm{C}-\mathrm{H}$ bond stretches of the excipients. The signal corresponding to the ABZ ester appears at $1740 \mathrm{~cm}^{-1}$, which is due to the stretching vibrations of the $\mathrm{C}=0$ bonds of glyceryl monostearate and Caprylic/capric triglyceride [16, 17]. 


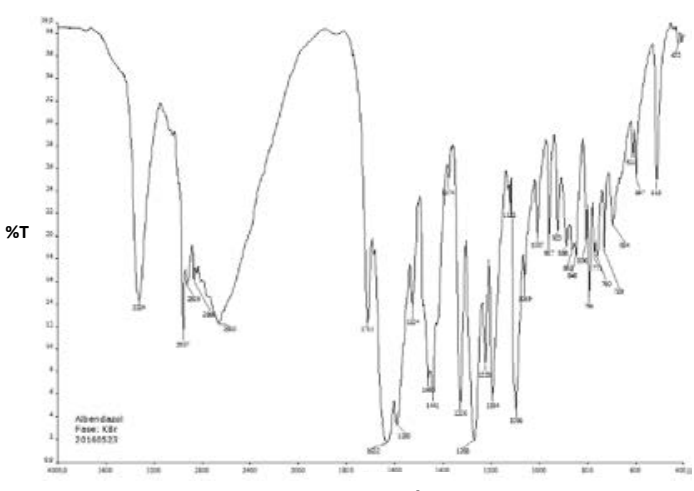

)

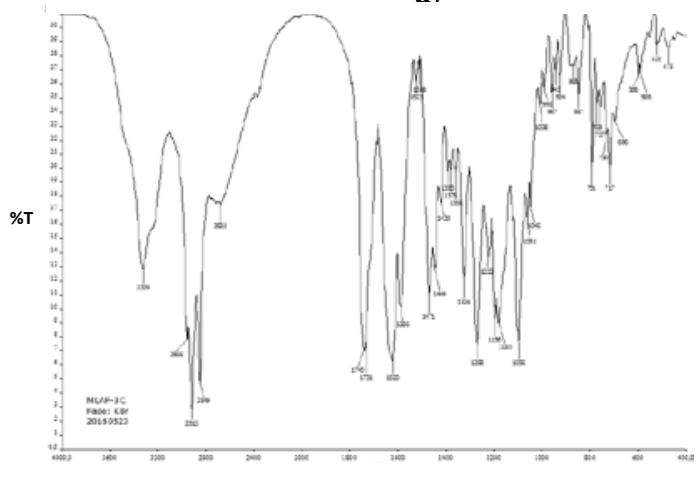

c)

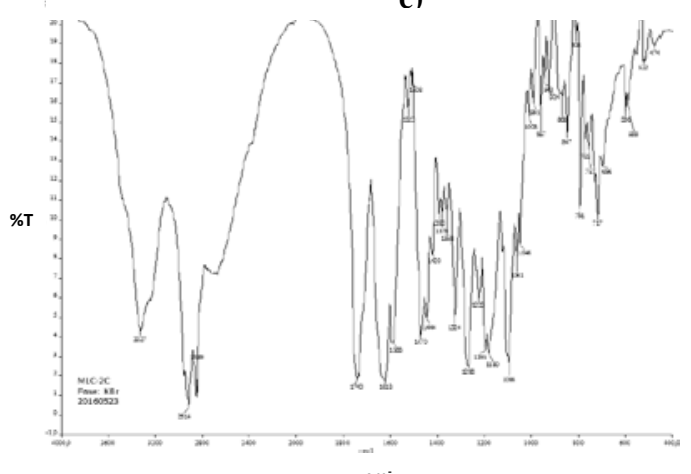

e)

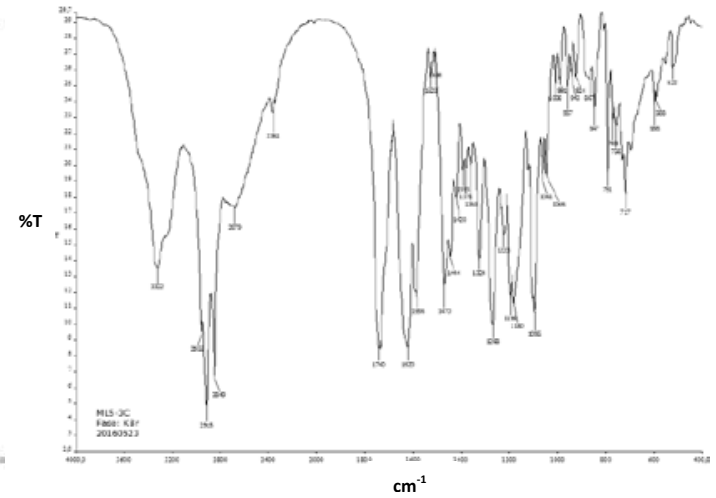

b)

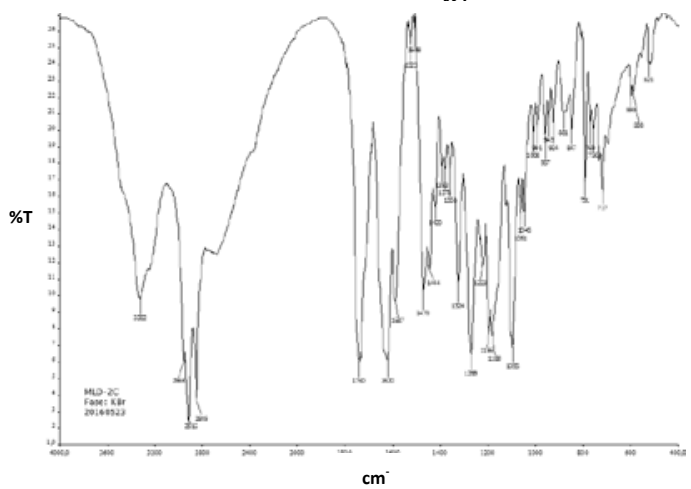

d)

Fig. 5: FT-IR spectra of Albendazole (ABZ) (a), F1 (b), F4 (c), F8 (d) and F11 (e)

Table 2 shows the results of the assays related to drug loading, encapsulation efficiency, and dissolution test. Regarding the dissolution test, in general, it is evident that the incorporation of the modifying agents increases the amount of dissolved ABZ, being the Aerosil $^{\circledR} 200$ at a concentration of $6 \%$ the excipient that improves the dissolution of the API at greater extent.

Table 2: Drug loading, encapsulation efficiency and dissolution test

\begin{tabular}{llll}
\hline Formulation & Drug loading (\%) & Encapsulation efficiency (\%) & Dissolution percentage (mean \pm SD) \\
\hline ABZ & - & - & $1.50 \pm 0.50$ \\
ABZ+surfactant & - & - & $11.45 \pm 3.21$ \\
F1 & $27.40 \pm 0.67$ & $80.24 \pm 1.96$ & $36.13 \pm 0.52$ \\
F2 & $27.11 \pm 0.79$ & $75.13 \pm 2.17$ & $19.94 \pm 0.23$ \\
F3 & $24.53 \pm 0.75$ & $76.38 \pm 2.35$ & $59.64 \pm 1.23$ \\
F4 & $21.17 \pm 0.48$ & $76.79 \pm 1.74$ & $85.96 \pm 1.17 *$ \\
F5 & $18.83 \pm 1.27$ & $75.15 \pm 5.07$ & $76.87 \pm 0.33$ \\
F6 & $26.76 \pm 0.50$ & $82.92 \pm 1.54$ & $69.54 \pm 1.91$ \\
F7 & $24.63 \pm 0.12$ & $72.63 \pm 0.35$ & $27.47 \pm 0.71$ \\
F8 & $26.25 \pm 0.23$ & $77.98 \pm 0.69$ & $57.77 \pm 0.43$ \\
F9 & $25.41 \pm 0.39$ & $78.58 \pm 1.20$ & $55.77 \pm 0.73$ \\
F10 & $25.70 \pm 0.49$ & $86.59 \pm 1.64$ & $64.03 \pm 0.69$ \\
F11 & $27.50 \pm 0.32$ & $89.46 \pm 1.06$ & $67.54 \pm 0.15$ \\
F12 & $23.74 \pm 0.42$ & $85.80 \pm 1.48$ & $67.74 \pm 0.88$ \\
\hline
\end{tabular}

Data given in mean \pm SD, ABZ: albendazole. $n=3 * p<0.05$ when comparing all groups. 
The incorporation of a liquid lipid in the solid matrix causes that the microstructure of the carriers becomes imperfect. In this case, this facilitates the release of the drug from the matrix [6]. During the cooling process, the solid lipid crystallize forming a small nucleus free of liquid lipid. Therefore, most of the caprylic/capric triglyceride is going to be located in the outer layer of the carriers. As the drug tends to be more soluble in the liquid lipid, this outer layer has a higher drug load that can be easily released by diffusion or erosion of the matrix [17].

It is important to mention that the incorporation of PEG 6000 into the lipid carriers has an important role in the release of the API. When the carriers are exposed to the dissolution medium, the PEG begins to dissolve, which favors the degradation of the matrix, increasing its porosity and facilitating the diffusion of ABZ into the dissolution medium [18].

Aerosil ${ }^{\circledR} 200$ can reduce the size and agglomeration of the particles, which increases the surface area, leading to an increase in the interaction of the carriers with the dissolution medium, favoring the diffusion of the drug to the medium [19]. Besides, it should be taken into account that the Aerosil ${ }^{\circledR} 200$ is hydrophilic and it will tend to hydrate [20]. Therefore, being dispersed in the carrier matrix, it will facilitate its hydration, increasing the contact of the carrier with the dissolution medium, and promoting the diffusion of the API.

The mechanism of drug release from our carriers can occur by diffusion and/or erosion of the matrix [17]. The mechanism of disintegration of crospovidone is related to swelling, porosity, and capillarity [21-23]. It could be thought that by obtaining lipid carriers with crospovidone dispersed in its structure, it would behave similarly. Upon contact with the dissolution medium, crospovidone will swell, producing the erosion of the matrix and entry of liquid into the carriers, which would explain the improvement observed in the dissolution of the API.

Besides the technological benefits provided by the designed carriers, such as the greater surface contact with the dissolution medium and rapid release of the drug from the matrix, the modification of crystalline structure should be considered as a determining characteristic. Many solid compounds can present polymorphism, due to their ability to form crystalline networks with different arrangements or conformations. The polymorphs of the same chemical compound, in addition to differing in the structure of their solid-state, they also differ in physical and chemical properties, which affects the stability, dissolution, bioavailability, and other characteristics of the drug [24]. In general, it is established that a solid in an amorphous state is easier to dissolve than the same compound on a state with an ordered crystalline lattice, since less energy is needed to distort its molecular network. The DSC and XRD assays showed a loss in the crystallinity of the API in the carriers developed, which is correlated with the improvements observed in the dissolution test.

\section{CONCLUSION}

The lipid carriers modified with Aerosil ${ }^{\circledR} 200$ (specifically when using the excipient at $6 \% \mathrm{w} / \mathrm{w}$ ), show the best results regarding the performance in the dissolution test.

The improvement in the drug release rate of ABZ can be attributed to the decrease in the crystallinity of the active ingredient in the formulations, as suggested by DSC and XRD assays.

From the infrared spectra and XRD of the lipid particulate carriers, where characteristic signals of the API are present, we can conclude that the interaction between the API and the excipients is only physical.

\section{FUNDING}

Nil

\section{AUTHORS CONTRIBUTIONS}

All the authors have contributed equally.

\section{CONFLICT OF INTERESTS}

Declared none

\section{REFERENCES}

1. Attama A, Igbonekwu C. In vitro properties of surface-modified solid lipid microspheres containing an antimalarial drug: halofantrine. Asian Pac J Trop Med 2011;4:253-8.

2. Bhoyar PK, Morani DO, Biyani DM, Umekar MJ, Mahure JG, Amgaonkar YM. Encapsulation of naproxen in lipid-based matrix microspheres: characterization and release kinetics. J Young Pharm 2011;3:105-11.

3. Kalepu S, Manthina M, Padavala V. Oral lipid-based drug delivery systems-an overview. Acta Pharm Sin B 2013;3:361-72.

4. Jannin V, Musakhanian J, Marchaud D. Approaches for the development of solid and semi-solid lipid-based formulations. Adv Drug Delivery Rev 2008;60:734-46.

5. Mayet L, Jung Cook H, Mendoza O, Rodriguez J. Estudio comparativo de perfiles de disolución de medicamentos del mercado nacional. Rev Mex Cienc Farm 2008;39:4-8.

6. Hu FQ, Jiang SP, Du YZ, Yuan H, Ye YQ, Zeng S. Preparation and characteristics of monostearin nanostructured lipid carriers. Int J Pharm 2006;314:83-9.

7. United States Pharmacopeial Convention. USP 40/NF35. Rockville (MD); 2017.

8. Albertini B, Passerini N, Gonzalez Rodriguez ML, Perissutti B, Rodriguez L. Effect of Aerosil@ on the properties of lipid controlled release microparticles. J Controlled Release 2004;100:233-46.

9. Rowe R, Sheskey P, Quinn M. Handbook of pharmaceutical excipients. $6^{\text {th }}$ ed. London: Pharmaceutical Press and American Pharmacists Association; 2009.

10. Susarla R, Afolabi A, Patel D, Bilgili E, Dave RN. Novel use of superdisintegrants as viscosity enhancing agents in biocompatible polymer films containing griseofulvin nanoparticles. Powder Technol 2015;285:25-33.

11. Padhye SG, Nagarsenker MS. Simvastatin solid lipid nanoparticles for oral delivery: formulation development and in vivo evaluation. Indian J Pharm Sci 2013;75:591-8.

12. Albertini B, Passerini N, Gonzalez Rodriguez ML, Perissutti B, Rodriguez L. Effect of Aerosil@ on the properties of lipid controlled release microparticles. J Controlled Release 2004;100:233-46.

13. Alanazi FK, El-Badry M, Ahmed MO, Alsarra IA. Improvement of albendazole dissolution by preparing microparticles using spray-drying technique. Sci Pharm 2007;75:63-79.

14. Gonzalez N, Castro S, Sanchez B, Allemandi D, Palma S. Albendazole solid dispersions: influence of dissolution medium composition on in vitro drug release. Dissolution Technol 2014;21:42-7.

15. Yurkanis P. Espectrometria de masas, espectroscopia infrarroja y espectroscopia ultravioleta/visible. In: Cruz L. editor. Quimica Organica. 5th ed. México: Pearson Educacion; 2008. p. 512-55.

16. Pavia DL, Lampman GM, Kriz GS, Vyvyan JR. Introduction to spectroscopy. 4th ed. United States of America: Cengage Learning; 2008.

17. Hu FQ, Jiang SP, Du YZ, Yuan H, Ye YQ, Zeng S. Preparation and characterization of stearic acid nanostructured lipid carriers by solvent diffusion method in an aqueous system. Colloids Surfaces B 2005;45:167-73.

18. Herrmann S, Winter G, Mohl S, Siepmann F, Siepmann J. Mechanisms controlling protein release from lipidic implants: effects of PEG addition. J Controlled Release 2007;118:161-8.

19. Mani N, Suh HR, Jun HW. Microencapsulation of a hydrophilic drug into a hydrophobic matrix using a salting-out procedure. II. Effects of adsorbents on microsphere properties. Drug Dev Ind Pharm 2004;30:83-93.

20. Castro Ruiz JM. Diseno de un sistema bioadhesivo de clorhexidina empleando pullulan como matriz para uso en mucosa oral. Colombia: Universidad Nacional de Colombia; 2014.

21. Hernandez Torres JE, Melgoza Contreras LM. Principales superdisgregantes sintéticos, mecanismos y factores que influyen en su actividad. Rev Colomb Ciencias Quimico Farmaceuticas 2014;43:234-47.

22. Mohanachandran PS, Sindhumol PG, Kiran TS. Superdisintegrants: an overview. Int J Pharm Sci Rev Res 2011;6:105-9.

23. Shihora H, Panda S. Superdisintegrants, utility in dosage forms: a quick review. J Pharm Sci Biosci Res 2011;1:148-53.

24. Yu LX, Furness MS, Raw A, Woodland Outlaw KP, Nashed NE, Ramos E, et al. Scientific considerations of pharmaceutical solid polymorphism in abbreviated new drug applications. Pharm Res 2003;20:531-6. 